\title{
Re-negotiating Exhibitionary Practices and the "Digital" Politics of Display: The Case of the MTL Urban Museum App
}

\author{
Ana-Maria Herman*
}

\begin{abstract}
In this paper, I employ a sociotechnical approach (drawn from science and technology studies) to reconstruct how the McCord Museum's MTL Urban Museum App was re-made. I take into account both the social and the technical, and consider the human and the nonhuman, which allows me to chart the roles of heterogeneous actors in re-making the App and in re-negotiating the Museum's display practices. In doing so, I explore and point to the politics of this "digital" display: What actors were involved in its re-making? How did they participate in decision-making processes? What are the implications of the negotiations made? The analysis reveals: 1 ) how the re-making of the App redistributed tasks associated with exhibitionary practices by displacing them across unexpected actors both inside and outside the Museum, 2) how some aspects of design can become 'non-negotiable' or 'irreversible', and 3) how the re-negotiation of display practices established unanticipated 'gatekeepers' in the Museum's display practice. Thus, this study sheds light on a "digital" case of the 'politics of display' (Macdonald, 1998).
\end{abstract}

Keywords: actor-network theory; exhibitionary practices; museum apps; politics of display

\section{Introduction}

With the introduction of digital media technologies in the museum context over the last decades, museum research and literature has placed increasing attention on "the digital". As Olesen (2016) points out, a significant number of researchers have contributed to this growing literature from a variety of perspectives, including digital heritage (Parry 2007, 2010), new media in museums (Henning 2006, 2007, 2011); app experiments in museums (Smørdal et al., 2014), and digital media design practices (Mason, 2015, 2016). But as Olesen (2016) also reminds us, while museum research and literature has placed an increasing concern on "the digital", there are few 'behind the scenes' investigations that shed light on the organizational practices and processes from which "digital" exhibits emerge. Examples of previous studies that have examined the 'behind the scenes' processes of how "material" exhibits emerge include those of Macdonald (2002) who investigated the making of the Food for Thought - Sainsbury Wing exhibition (hereon Food for Thought), in Behind the Scenes at the Science Museum, and Yaneva (2003) who explored how a Volkswagen bus came to be a museum exhibit, named Mückenbus. These particular studies are important to this paper since they approached their 'behind the scenes' studies by employing actor-network theory (ANT), and I also draw on ANT in this 'behind the scenes' research study.

In both Macdonald (2002) and Yaneva's (2003) studies, ANT provides a way to take into consideration more than just human involvement in exhibitionary processes and practices. In her ethnographic study of 'how a bus met a museum', Yaneva (2003) employs the ANT dictum 'follow the actors' to examine the production of a contemporary art installation. Her stated aim is to avoid seeing the museum from the outside, as 'instrumental' (an approach often applied in museum studies) ${ }^{1}$, nor from the inside, seen for its 'internal principles' (a view suggested as held by anthropologists of material cultural $)^{2}$. Rather, Yaneva (2003) examines the museum both 
from the outside and the inside, and as a 'quasi-technical network'. For Yaneva, '[i]nstitutional theories and material culture studies have rarely addressed the fact that the museum before the opening ceremony of the show, is a strange messy world composed of heterogeneous actors with a variable ontology' (2003: 117). Thus Yaneva proceeds to 'explore the dynamic process of negotiations around different material rearrangements' (Yaneva, 2003: 117), by following the installation of a bus and revealing how it is rendered as 'art'. By doing so, her analysis makes visible 'how a multitude of tiny infinitesimal operations bring the museum into existence' (Yaneva, 2003: 117). Macdonald's (2002) study, on how the Food for Thought exhibition was made, similarly observes a broader set of actors beyond the Science Museum's walls, and also demonstrates a complex set of negotiations between heterogeneous actors that are entangled over space and time. But of particular relevance here is that Macdonald's (2002) findings shed light on the implications of such entanglements - for example, the Sainsbury-sponsored Food for Thought exhibit showed us that the commercially interested players do not only "sponsor" exhibits but may also have a say in what goes in them, thus unveiling exhibition-making as a practice that is intertwined with politics both inside and outside the museum. And likewise, the present case will show that only by tracing actors beyond the museum can we best reveal the negotiations and operations that lead to its entangled "digital" politics.

There are other studies that have employed ANT in relation to understanding or analyzing museum-related objects, practices and processes (for example, see Star and Greismer, 1989 on 'boundary objects' or Stuedahl and Smørdal, 2011 on 'museum assemblies'), but much more behind the scenes research is needed. In particular, there is little literature that takes into account the 'politics of display' - the main concern of Macdonald's (1998) edited volume on science exhibitions with the same title - that is specific to making "digital" displays and exhibits. ${ }^{3}$ Macdonald, considers 'politics' in the 'broad sense of the workings of power', pointing to Michel Foucault's observation that 'power and knowledge are thoroughly mutually implicated' (1998a: 3). As such, the politics of display refers to the 'production, distribution and consumption of knowledge'- not only about the knowledge on display, but also 'the knowledges (including unreflected-upon assumptions) of different parties involved in exhibition-making, their attempts to, for example, gather knowledge about visitors, and the understanding of visitors themselves' (1998a: 3). Display politics thus 'lies not just in policy statements and intentions (though these are important) but also in apparently non-political and even "minor" details, such as the architecture of buildings, the classification and juxtaposition of artefacts in an exhibition, the use of glass cases or interactives, and the presence or lack of a voice-over on film' (Macdonald, 1998a: 3). It is in the competing social, cultural, economic and political interests of diverse players and the negotiations of heterogeneous actors that we may find the politics of display, but research on the politics of how "digital" displays or exhibits are made is sorely lacking.

This paper looks to help fill in some of the gaps in literature through a case study - by reconstructing how the McCord Museum's MTL Urban Museum App (hereon the MUM App or App) got re-made. The MUM App was a novel location-based 'augmented reality' app when introduced by the McCord Museum, in 2011, as a way to showcase a selection of digitized images from its extensive photographic collection called the Notman Photographic Archives, as well as to promote the reopening of its permanent exhibition, Montreal - Points of View. ${ }^{4}$ The MUM App's particular novelty lay in the way in which it used location-based technologies to display historical photographic collections in 'augmented reality' - by superimposing digitized historical photographs onto cityscapes to show how sites of the city looked before. It also allowed 'museum visitors' to view the collection on their own, as the App is downloaded to their personal mobile devices. It was the first of its kind released by the Museum and the first deployed by a museum in Canada. ${ }^{5}$ But, while it was 'novel', it was not the first to be made in the world: just over a year earlier, the Museum of London released the Museum of London: Streetmuseum ${ }^{T M}$ App (hereon the Streetmuseum App) - what would be the MUM App's predecessor. The 'success' of the Streetmuseum App (i.e. it's reported 65,000 downloads in the first four weeks) ${ }^{6}$ and its novel way of presenting photographic collections (as well as the convincing reports read by the Museum, described below) would all appeal to management personnel the McCord Museum, who would contact its creators, Brothers and Sisters, to develop a similar app - a reason I discuss the MUM App as being "re-made" rather than "made", or 
we could say in ANT terms 're-negotiated' (Latour, 2005; Law, 2007; Law, 2008) and in new media studies 'remediated' (Bolter and Grusin, 1999).

To reconstruct how the MUM App was re-made, I draw on semi-structured interviews and documentary analysis, and take a 'sociotechnical approach' drawn from ANT that avoids technological determinism (the view that technology changes culture and society) or constructivist approaches (the flip side, that humans do so). This case and approach allows me to: 1) chart the roles of heterogeneous actors in re-negotiating the Museum's exhibition-making practices, and 2) point to the politics arising from re-making this particular App. The purpose here is not to critique the actors involved, as much as to reveal them, showing how the re-negotiations involved in this case redistributed tasks associated with the Museum's exhibition-making practices (displacing them across actors inside and outside the Museum), how some aspects of design became 'non-negotiable' or 'irreversible' and how unexpected 'gatekeepers' (both human and nonhuman) were established in the Museum's display practice - thus unveiling a case of "digital" politics of display.

\section{The Theoretical Framework}

The theoretical framework is drawn from science and technology studies. It has been noted before that the museum can be seen and understood in the same manner as the scientific laboratory (Yaneva, 2003 on Latour and Woolgar's, 1979, 'laboratory life'), but such studies also provide us with an approach to understanding digital media technologies. Studies of social and cultural change related to emerging technologies have often been entangled with debates about technological determinism, which focus on technologies as agents of change, and constructivist approaches, which focus on humans as agents of change (Akrich, 1992; Law and Bijker, 1992; see also Parry, 2007 and Olesen, 2016 who discuss these debates in relation to the museum; and also Lister et al. 2009 on how this debate relates to new media studies). As Akrich explains, taking one or the other approach ultimately leads to only half the picture:

...technological determinism pays no attention to what is brought together, and ultimately replaced, by the structural effects of a network. By contrast social constructivism denies the obduracy of objects and assumes that only people can have the status of actors. The problem is not one of deciding whether a technology should be seen as an instrument of progress or a new method for subjugating people. It is rather to find a way of studying the conditions and mechanisms under which the relations that define both our society and our knowledge of that society are susceptible to partial reconstruction (1992: 206).

Put another way, 'all relations should be seen as both social and technical' and as such, social constructivism and technological determinism are flawed 'because neither the (purely) social nor the (exclusively) technical is determinant in the last instance' (Law and Bijker, 1992: p. 290). Instead of thinking of technologies as 'purely' technological, Law and Bijker (1992) point to how they are heterogeneous (see also Latour, 1991, on the discussion of the 'purification' of hybrids).

To avoid the pitfalls of technological determinist views or constructivist approaches, I take a sociotechnical approach to examine how the MUM App emerged (as an actor-network). Here, I employ the ANT principle of 'symmetry', (Latour, 1987; Law and Bijker, 1992; see also Latour and Woolgar, 1979) that considers both humans and nonhumans on the same terms; and actor-networks are here considered as emerging from complex 'sociotechnical' systems (Law, 1991; see also Bijker and Law, 1992) or networks of 'heterogeneous' actors that bring together 'actants of all types and sizes, whether human or nonhuman' (Akrich, 1992 p. 206; see also Latour, 1994; Law and Bijker, 1992; Law, 1991). As such, the social, cultural and political implications of the negotiations between a network's heterogeneous actors are understood as being 'relational effects' - as consequences of the negotiations between a network's actors (Latour, 2005; Law, 2007; Law, 2008). Taking a sociotechnical approach allows me to render visible a host of (sometimes unexpected) heterogeneous actors involved in re-making the MUM App (i.e. how this actor-network emerged) as well as to examine how the politics of display played out in relation to this "digital" exhibit. 


\section{The Research Methodology}

The findings in this case study are drawn from semi-structured interviews with management personnel at the McCord Museum, which were conducted during a one-year research residency. I also subsequently interviewed personnel at two UK-based companies, Brothers and Sisters (a lively and innovative advertising agency) and Thumbspark Ltd. (a small app development company) involved in re-making the MUMApp (and the Streetmuseum App before it). WhileANT studies often employ ethnographic methods when 'following the actors' (the ANT dictum applied by Macdonald, 2002 and Yaneva, 2003), the approach of 'reconstructing' how a process unfolded by interviewing key informants has also been taken before in ANT studies. For example, while Macdonald (2002) did follow team members who participated in making the Food for Thought exhibit, she also 'carried out semi-structured interviews with many other Museum personnel' who were involved in exhibition-making (both the Food for Thought exhibit and others being planned during her field work). But with multiple meetings going on at the same time and in different places, and with the challenge of gaining permission to attend meetings, Macdonald had to choose between who, what and where to follow. Ultimately, it is not possible to follow all the actors as one cannot be following many, nor all, actors at the same time, nor across space and time (see also Rubio, 2012, on reconstructing the process of culture in the making, the case of the Spiral Jetty). In my case, the timeframe of the research was the major obstacle - I began my residency about a year after the MUM App had been released on the App Store. As such, the analysis relies on the semi-structured interviews held with key informants (i.e. the interviewees at the McCord Museum, Brothers and Sisters and Thumbspark Ltd) and the documents they provided (i.e. external reports, cases and whitepapers they read, as well as internal documents and photographs). In order to keep some level of anonymity, I have used the title of the roles of key informants, rather than their names.

At the McCord Museum, I interviewed the Head of IT on two occasions and the Project Manager of Web and Multimedia on two other occasions about how the MUM App was re-made. The Head of IT provided me with reports (including an early edition of a Horizon Report) and a whitepaper (on early augmented reality apps displaying historical photographic images). The Project Manager of Web and Multimedia, who had been more closely involved in re-making the MUM App, provided me with a detailed description of the process undertaken, as well as project documents and photographs that gave visual and practical insights into that process. I also had discussions with other personnel at the Museum, including the Head of the Marketing Department and her direct reports (who had minimal to no involvement in re-making the MUM App), as well as the Project Manager involved in refurbishing the Montreal-Points of View permanent exhibit (who had been involved in some decisions, such as the selection of collections, for the MUM App). Outside of the Museum, I interviewed a Digital Producer from Brothers and Sisters on one occasion, who described the process of re-making the MUM App from her agency's perspective, as well as aspects of how the Streetmuseum App (the MUM App's predecessor) was made before it. I also interviewed a developer from Thumbspark Ltd., who provided aspects of the developers' involvement in the processes of making both of the apps. Altogether, the interviews and documents provided helped to piece together a sufficient (though due to the enormity of the task never a complete) picture of how the MUM App was re-made, as well as (some) indications of its politics.

\section{How the MUM App Came to be Re-Made: A Re-Negotiation of Exhibitionary Practices}

The following discussion is on the findings of this study and is organized around the processes related to re-making the MUM App - including how it was decided to re-make the App, how collections were selected for its display and how digitized historical photographic images were labeled or described - pointing to how the Museum's exhibitionary practices were re-negotiated throughout these processes.

\section{Negotiating What Displays Get Re-made}

One of my first interviews at the McCord Museum was with the Head of IT, and he shared with me diverse reports, including editions of the Horizon Report developed by the New Media 
Consortium or NMC (which discussed emerging technologies that museums and other culture and heritage institutions should consider) and a whitepaper called 'Implementing Mobile Augmented Reality Technology for Viewing Historic Images' (that discussed early explorations with mobile apps and augmented reality by the Philadelphia Department of Records). In particular, the Horizon Report made a rather urgent case for museums (and other culture or heritage institutions) to consider developing apps - and specifically, apps that use locationbased and augmented reality technologies, which are enabled by features on mobile devices:

....we will begin to see widespread adoptions of two technologies that are growing in popularity in the consumer sector: augmented reality and location-based services. Museum educators arguably have always been in the business of augmenting reality, creating bridges between objects, ideas, and visitors, but augmented reality technologies are now allowing this to happen more fluidly and easily than ever. Location-based services offer museums to extend conversations about history, art, science, and more out into their communities, effectively extending the galleries to include public works, historical sites, and much more. Within the next few years, the opportunities offered to museums via the adoption and creative implementation of these two technologies will only expand. Consider a museum environment in which visitors can access deep, rich experiential learning, information, and services in a range of formats, each presented at the exact time and place when it is most meaningful — even beyond the boundaries of the museum itself. (Johnson et al., 2010: 6-7)

The direction towards using these types of app technologies was seen as a result of the soaring popularity of mobile devices, and particularly 'smart phones'. And these points were later reinforced in the whitepaper, which described how to showcase photographic collections using augmented reality apps - explaining at great length how these apps can work in relation to location-based technologies and how to use them to display collections of historical images across cities. ${ }^{7}$

These weren't the only reports, whitepapers or research papers describing the use of augmented reality apps from museums that were surfacing at the time (for example, see also Boyer and Marcus 2011), but both the report and whitepaper mentioned above were important to the Museum's personnel - perhaps not only in making the initial decision to re-make the app, but also to help explain and make a case for why they did so. This is again because the Horizon Report made convincing arguments for augmented reality apps, for example, as having 'become something anyone can use, thanks to the convergence of three technologies - GPS, video, and pattern recognition' making it 'a portable tool for discovery-based learning that can enhance the information available to patrons when visiting galleries, exploring outdoor installations, or interacting with real-world objects' (Johnson et al., 2010: 7). In distributing such convincing information to the museum community - and particularly to the McCord Museum this report acted not only as a 'mediator' but more importantly as a 'negotiator' in the decisions about what "digital" display would get made - or re-made. In the case of the McCord Museum, a combination of these and other cultural heritage media reports would not only bring locationbased augmented reality app technologies to their attention, but also point particularly to the Streetmuseum App as a 'successful' app, which would become another 'negotiator' not only in the decision to re-make the app, but also in its design and development.

The Streetmuseum App had been deployed in May of 2010, and shortly thereafter, it was reported to have been downloaded 65,000 times in the first four weeks after its release, well surpassing the Museum of London's initial goal of only 5,000 downloads (see note 6). It had received a significant amount of attention not only from audiences who downloaded the App, but also from the media and the museum community. This is, in part, because it was meant to serve as both an 'exhibit display' of the Museum of London's digitized historical collections and a 'promotional tool' for the Museum's reopening of its refurbished permanent exhibit, Galleries of Modern London (i.e. it had 'variable ontology' that stabilized at times with successful 'translation') ${ }^{8}$. Upon learning about the success of the Streetmuseum App, the McCord Museum would draw parallels between itself and the Museum of London. Both are city museums depicting local history through their collections and both have significant historical 
photographic archives. Further, the McCord Museum was coincidentally overhauling its own permanent exhibit, to be called Montreal - Points of View, and the Museum considered that it too could benefit from deploying a similar app to promote the reopening of its permanent exhibit (in late 2011). Interested in making an augmented reality app display (and particularly one that would be considered 'a Canadian museum first'), in late 2010 the McCord Museum contacted London-based advertising agency Brothers and Sisters to develop an 'exhibit display' / 'promotional tool' similar to the Streetmuseum App - and, in turn, Brother and Sisters engaged the Cambridge-based app development company called Thumbspark Ltd to code the App. Thus, these British-based actors, otherwise unlikely to be involved in a Canadian museum display, came to participate in, and 'negotiate', the re-making of the Streetmuseum App into the MUM App.

\section{Re-negotiating the 'Curation' of the MUM App}

Those of us not privy to how things work at a museum may assume that 'curators' are always involved in making exhibit displays, but not so says this case. The re-making of the MUM App was considered at the McCord Museum more so a 'multimedia project' than an 'exhibition' (showing that, in this case, one translation could be more successful than another!). As a result, the project was assigned to the Project Manager of Web and Multimedia. Also involved was a Project Manager for the Montreal - Points of View exhibit (given the MUM App was planned as a 'promotional tool' for the reopening of this permanent exhibition too) and the Senior Cataloger of the Notman Photographic Archives collection (from which most of the content for the MUM App would be selected). The Project Manager of Web and Multimedia was working on multiple projects at the time, and the other two team members had other responsibilities, leaving them with limited amounts of time to dedicate to this project. At the same time, there was pressure to complete the project within a relatively short period, and in particular, before the reopening of the permanent exhibit. But limited funding prohibited the Museum from hiring more personnel to work on the project. As such, an intern at the Museum was assigned the task of selecting, writing and preparing content for the display, releasing both the Project Managers and the Senior Cataloger from day-to-day involvement with these activities. Instead the more senior personnel would oversee these tasks, participating to varying degrees in some decisionmaking processes, such as by reviewing and/or approving the work of the intern. So while making "material" exhibits may, in other cases, involve one or more 'curator(s)', in this case, none were involved. This reveals two things. Firstly, how 'categories' are here actors too (see Bowker and Star, 1999; see also Star and Greismer, 1989) as this project's classification as a 'multimedia project' instead of an 'exhibition' meant it would be assigned, in the first instance, to the Project Manager of Web and Multimedia. Secondly, this case points to how roles and tasks may be redistributed in the midst of 'remediating' an actor-network. Here, curatorial roles and practices were redistributed, or in another word, 'displaced' (Latour, 1994) across diverse actors (or Latourian 'actants') and, as I will next explain, well beyond the Museum's organization.

'Curating' the MUM App display became not only a task that involved a team of three senior personnel at the Museum and an intern, but also a much wider range of unexpected actors. For example, the intern selected historical photographs from a range of images in the Museum's archives that had already been digitized. Therefore, the material form (and in this example, the digitized form) of images in the collection acted as a negotiator in the selection of images for display. Upon selecting digitized objects that could potentially be displayed, the images were printed and laid out across a large paper map in order for the team to take decisions (see Figure 1). By laying the selected images over the map, the team could then make decisions about the spread and fit of photographs across six particular zones they identified in Montreal: Sherbrooke Street West, Sherbrooke Street East, St Catherine Street, McGill University campus, Mont Royal and Old Montreal. In this way, city location also became a negotiator in what the MUM App would display. This practice of using spatial frameworks was also used at the Museum for "material" exhibits such as for the Montreal - Points of View, for which city zones were used to demarcate display spaces in the exhibition room and to select and organize objects from the Museum's collections. 


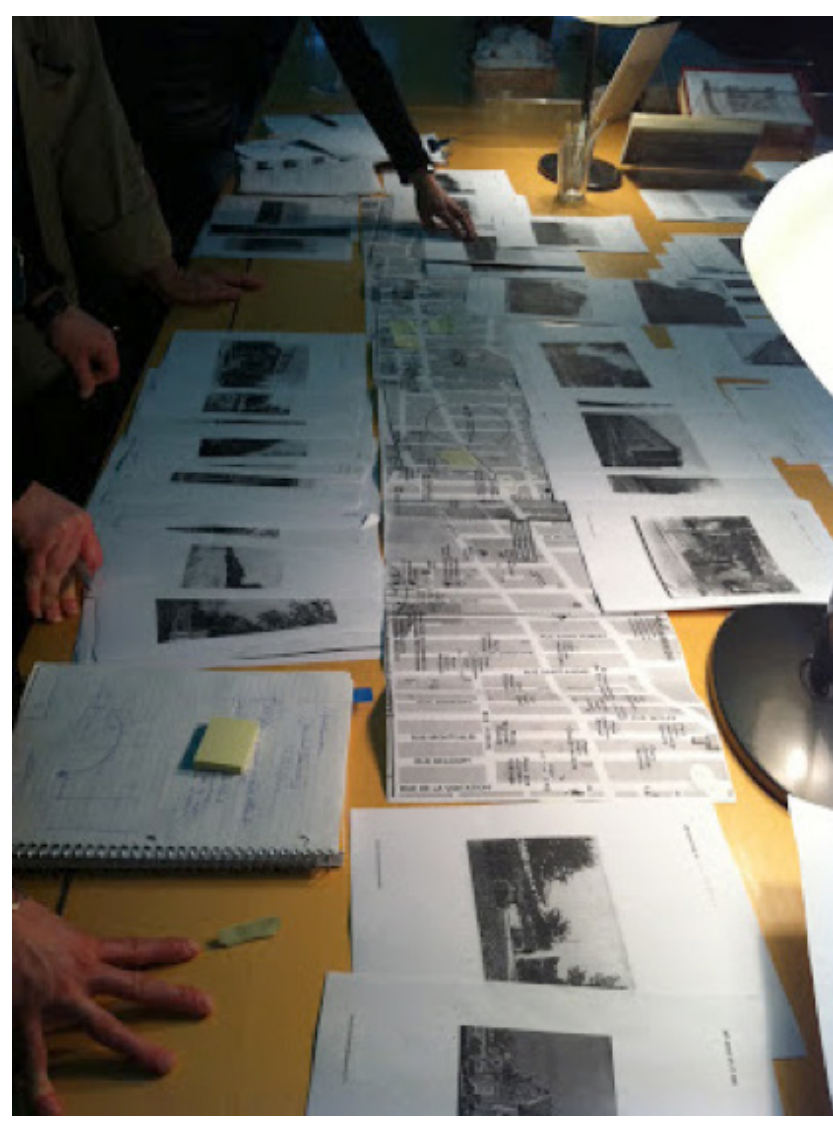

Figure 1. Deciding what will be displayed and where

As can be seen in Figure 1 , the process of re-making this "digital" exhibit involved materialssuchas'stickynotes'to inscribe information, notebooks to outline plans and pens to write with. Meetings happened in rooms where "material" objects, such as maps and photocopied images, could be laid out on tables where teams could work together hands on. At the same time these processes were complemented by interactions with, for example, data files that could be e-mailed. Communications were often e-mailed from the Museum in Montreal to the advertising agency in London, and from the advertising agency to the developer in Cambridge (and back). But such "digital" practices and processes did not, in this case, replace what was "material", rather these more recent sociotechnical practices (such as e-mailing), actors (for example, electronic documents or files) and negotiations (like the size limitations of file attachments that could be sent via different email platforms) were still very much embedded in the 'sociomaterial' (Suchman, 2007; see also Gillepie et al., 2014). Like in Suchman's (2007) study of Cog the intelligent or 'smart' machine, behind the "digital" are the (invisible) human labours and the "material": fingers click-clacking on keyboards of various computing devices in office spaces and the like. And the recent practices noted above were done side by side with longer-standing exhibitionary practices (such as jotting notes down on paper and meeting in rooms at the Museum). Thus it is the work of 'purification' (Latour, 1991) that categorizes and assigns objects, practices and processes as either "digital" or "material".

This already hints at how some aspects of re-making this "digital" display had much in common with the way in which "material" exhibits are made. Consider this example: space in exhibitions (such as floor space and glass cases) can act as a negotiator in making "material" exhibits, but screen space and device memory can similarly negotiate the content of a "digital" display. So while one might assume that the possibilities for display are endless for a "digital" exhibit, it is simply not so. In this case, the titles for each historical image were limited to a 60-character title and their descriptions to 250 characters in order to fit the already designed screen (much like labels on glass cases or descriptions on exhibit panels). And the overall memory space on the device acted as a negotiator in relation to how many images could be included on the MUM App (much like the space inside an exhibit hall). But space was not the only negotiator here as the decision itself to package digitized photographic objects on the App, instead of having them dynamically retrieved from an external repository, also negotiated how much content would be displayed. Packaging objects inside the MUM App limited the number of initial images displayed to a total of 141 historical photographic images - of these, 


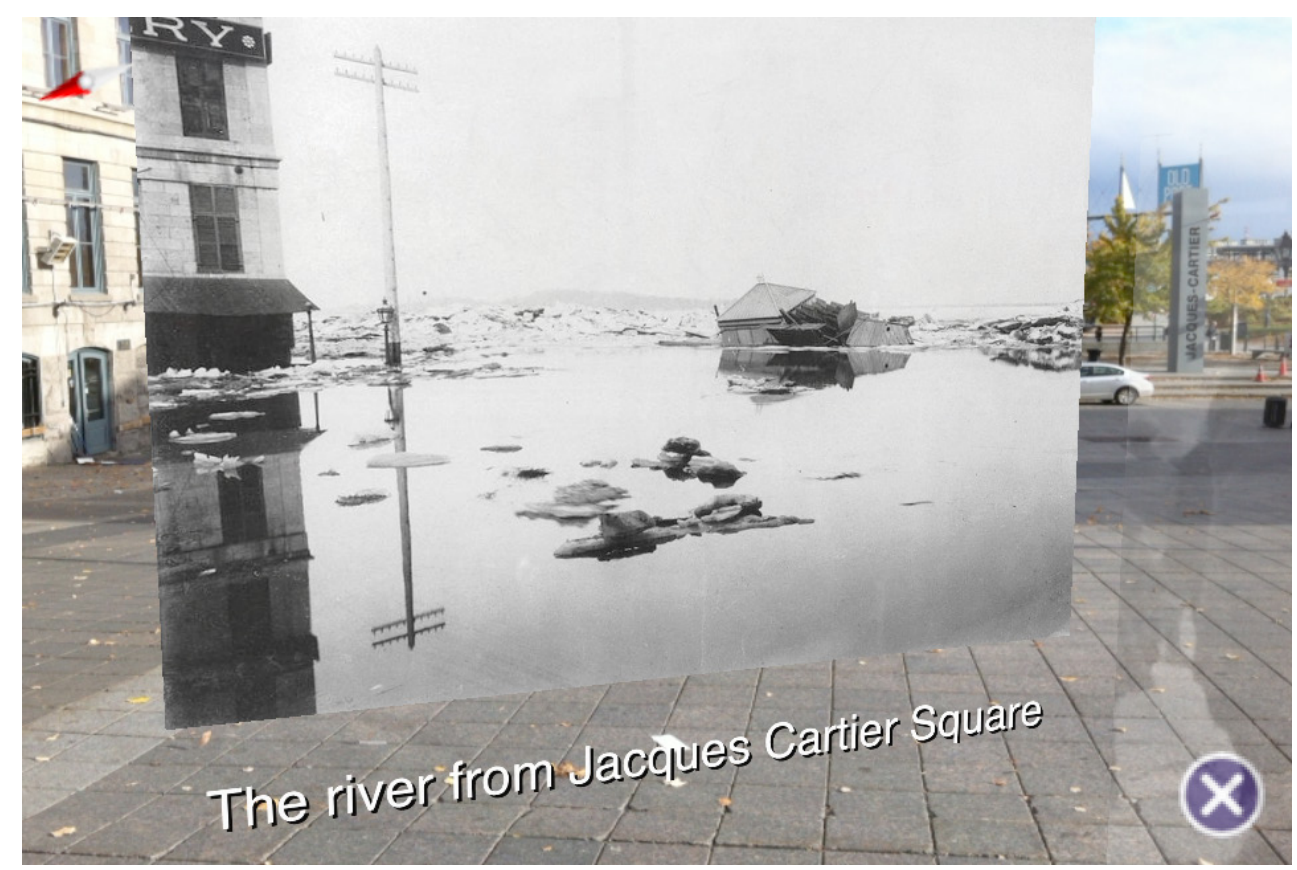

Figure 2. 'The river from Jacques Cartier Square' - in 3D display

124 images would be displayed in augmented reality and 17 images in two-dimensional (or $2-D$ ) presentation. These were selected from the Museum's archives of about 80,000 digitized photographs.

As mentioned, the photographic images selected for the MUM App corresponded to six particular zones selected in central areas of the city. These zones included historical sites that happened to be the subjects depicted in the historical photographs. But perhaps just as significantly, these historical areas of interest were often visited not only by locals in their everyday life, but importantly here, by "tourists" visiting the city. "Tourists" are one type of visitor to the Museum and were here considered as a potential audience for the MUM App. This is similar to the findings of Macdonald's (2002) study on the Food for Thought exhibit, in which 'imagined audiences' (i.e. speculation on who would be interested in seeing the display? and what would they want to see or know?) had acted as negotiators in decisions on what to display. In this case, imagined audiences acted as negotiators in deciding where objects would be best displayed (i.e. in which "historical" or "tourist" zones), what historical photographs it would be aesthetically pleasing to view and what would be interesting to know about them. By speculating what tourists or museum visitors (or other potential audiences) may find interesting, diverse themes were developed for selecting images from the larger digitized collection. For example, it was decided that "natural disasters" as a theme would be interesting to see in the exhibit. And given that photographs of natural disasters were abundant in one of the main zones selected - specifically, in and around the area of Old Montreal - many historical images selected for display depicted events such as floods, fires and icy conditions (for example, you can see the flooded river from Jacques Cartier Square in Figure 2-displayed here in augmented reality). But this wasn't the only way in which imagined audiences negotiated what would be on display. The descriptions of each display image were also written in relation to what imagined audiences might do. For example, in Figure 2 'Miss Grant sitting on the balustrade' we see a caption below that invites the viewer to 'Come and have your picture taken with Miss Grant!'.

Furthermore, only those photographic images that could be viewed in the same position as the photographer who had taken the original image would be selected, in order to support the alignment of the photographic displays as overlays onto city views. So bodies (both of 


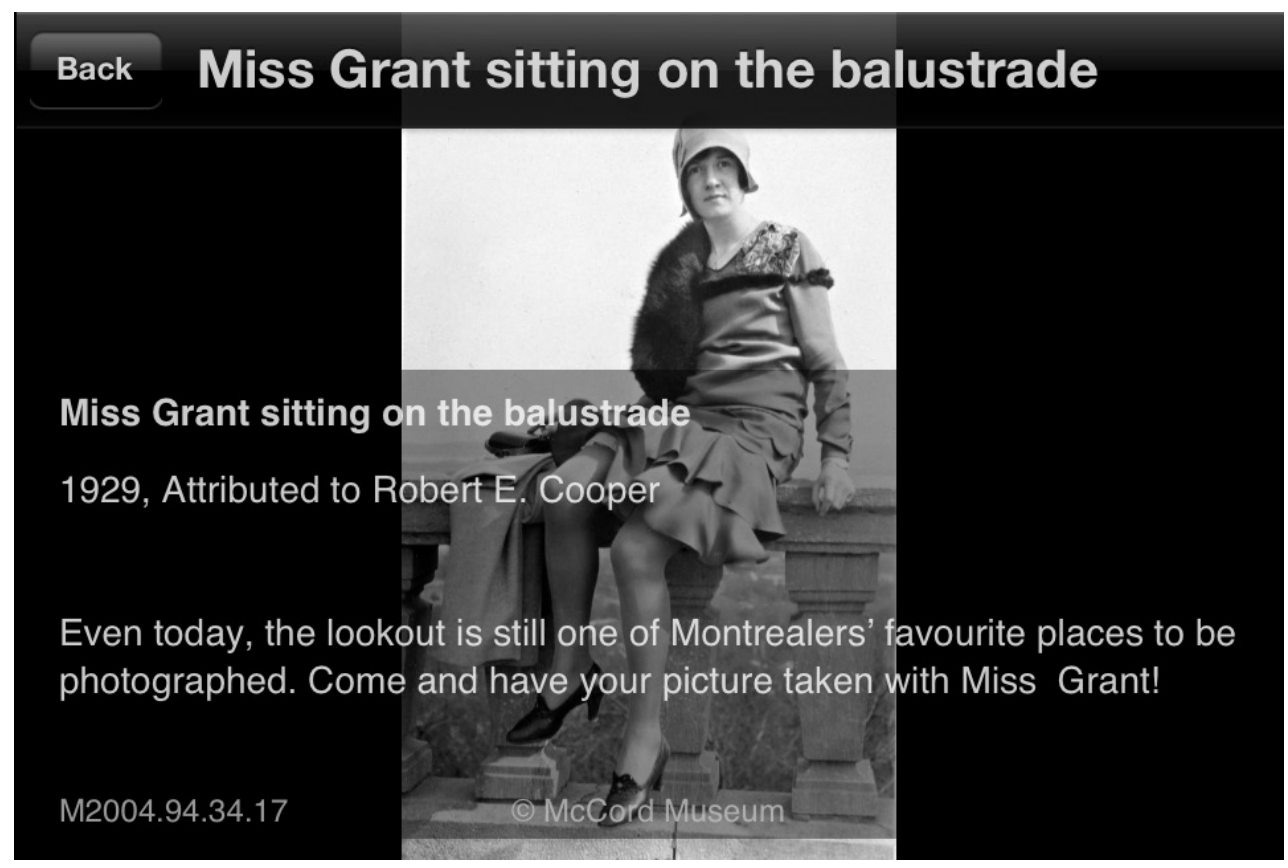

Figure 3. 'Miss Grant sitting on the balustrade' - in 2D display

the original photographer and the imagined audience) acted as negotiators in the selection of images for display. Bodies also worked in concert with specialized cameras in order to encode each digitized image with relevant metadata. This is because the augmented reality technology used for the MUMApp requires geo-locational and geo-spatial information to present the location of images on 'pinned cards' (a map view on which the 'pins' provide the locations where collections may be viewed in the city) and to display images in 3-D view (the augmented reality view that superimposes photographic images onto city views). The geo-locational data (longitude and latitude) allows the technology to place 'pins' across the pinned card and, when combined with the geo-spatial data (cardinal direction), provides the coordinates for 'pinning' the digitized object in 3-D view. To encode this information, a Sony DSC-HX5V camera was used, which comes outfitted with a GPS receiver and compass that collects and encodes the coordinates for digitized objects. ${ }^{9}$ There was also a 'test build' app that was developed and employed as a way to determine whether the geo-locational and geo-spatial coordinates of the digitized objects were placed well in augmented reality (i.e. as 3-D superimpositions). The test build app was held up in each location where a digitized object would be displayed to verify its placement - and it recorded a "good" or "poor" rating relative to each superimposition (see figures 4 and 5). Of course, the city's architecture also played an important part - indicating, to the pattern recognition technologies of these various devices, how to place the digitized objects in augmented reality. But, again, while such nonhuman actors are found to have played a role in these processes, the practices performed all required bodies for the tasks to be completed. It involved Museum personnel, such as the intern, walking to each location in the city and positioning the body in relation to diverse devices in order for the required information to be captured and discerned. This method had been used before in the case of the Streetmuseum App. Though, as the Digital Producer at Brothers and Sisters explained, in London there was a significantly wider city-area to cover, so it required 'ten runners using London's "Boris bikes"' (the colloquial name for the city's cycle hire system) to get around the sprawling city and collect this type of information for the "digital" display. Throughout, both humans and nonhumans were involved in not only how the App would be re-made but also how exhibition-making practices would be re-negotiated and redistributed (inside and outside the Museum). 


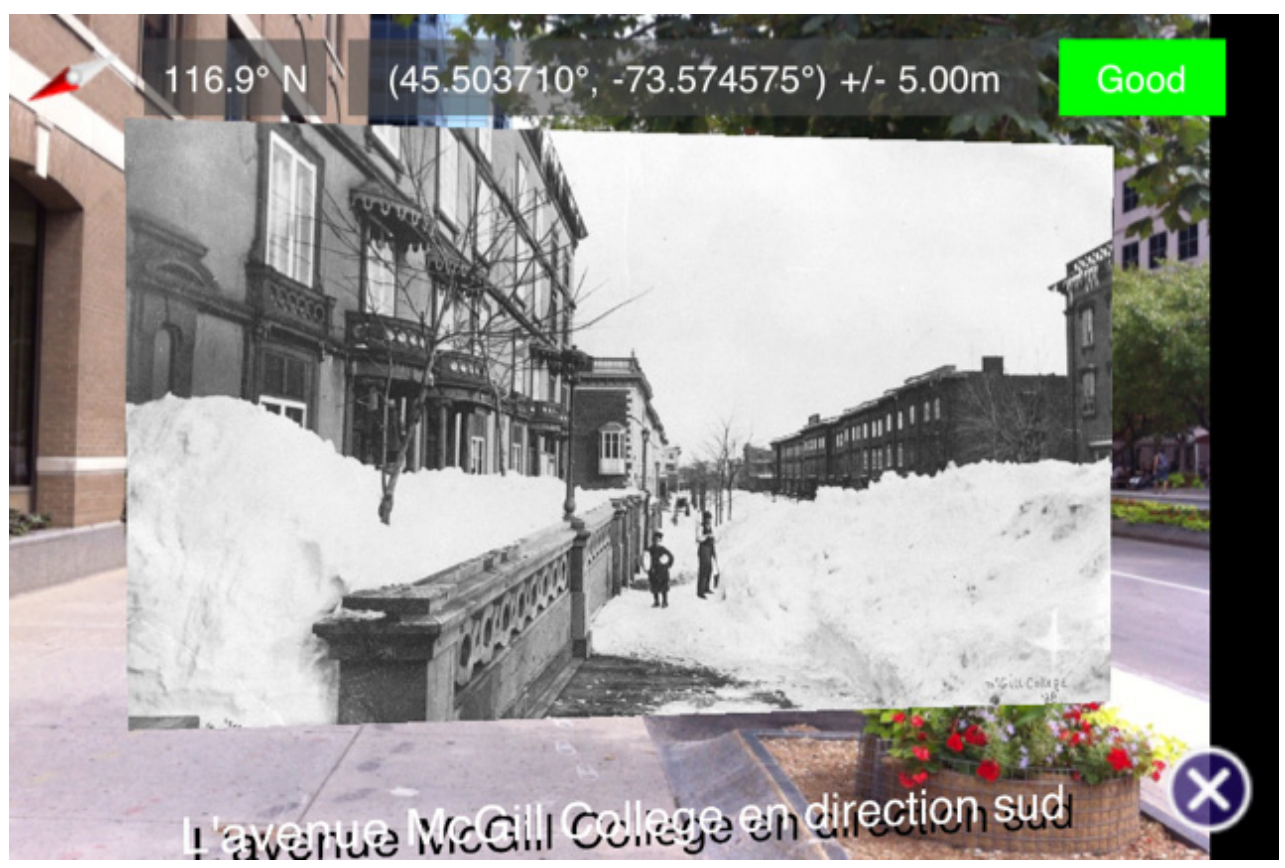

Figure 4. Good superimposition, Courtesy of the McCord Museum

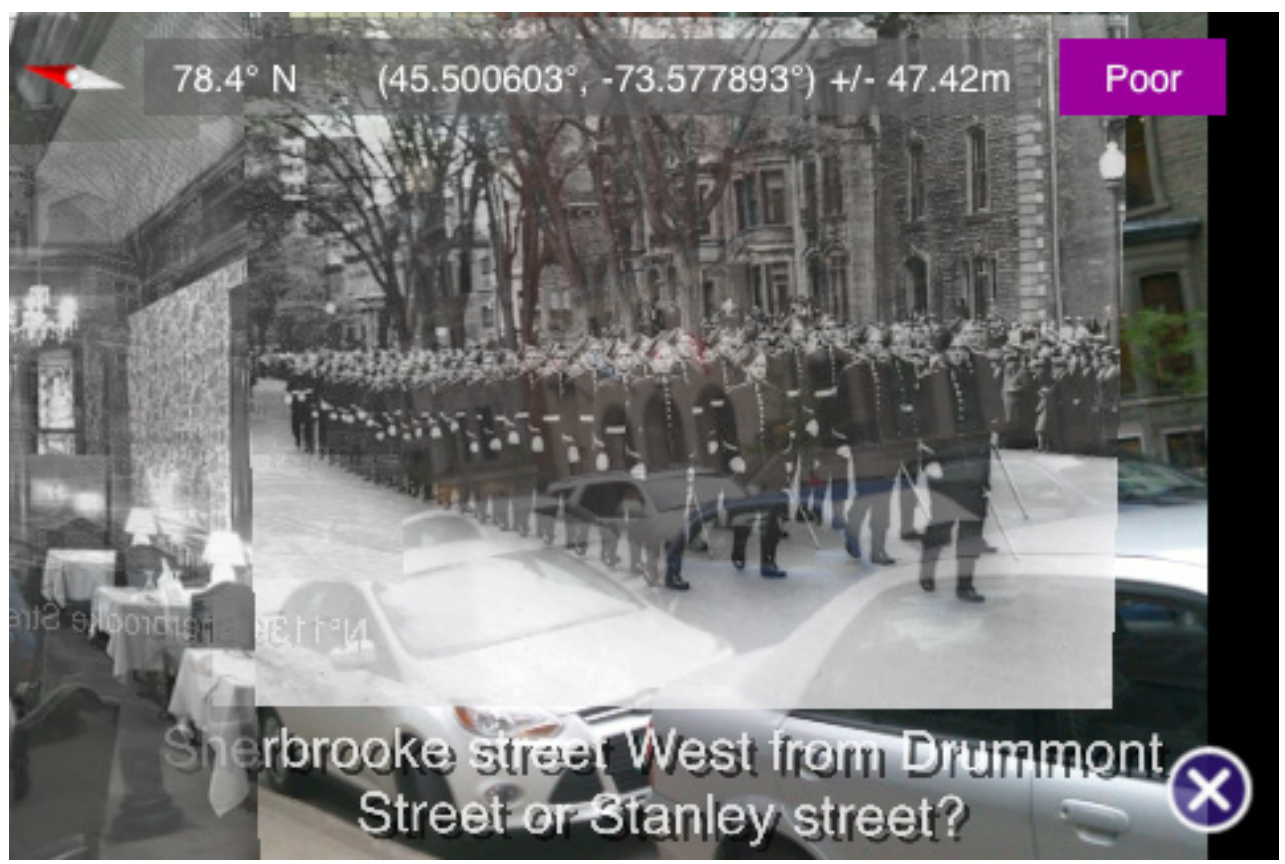

Figure 5. Poor superimposition, Courtesy of the McCord Museum 


\section{The "Digital" Politics of Display: On Irreversibility and Emerging Gatekeepers}

The aim of this section is to discuss the "digital" politics that arose in re-making the MUM App display. However, by now, the challenge in doing so should be evident: it is difficult, if not impossible, to untangle the "digital" from everything else that is "material" or "human". Yet, there are two observations that can be made about the politics of app development as exhibition-making: 1) how aspects of design can become 'irreversible' or 'locked in' and 2) how unexpected 'gatekeepers' can be established in the 'black-boxed' process of making apps.

\section{The Non-Negotiators: How Components of Design Become Irreversible}

While diverse actors - including museum personnel, marketers, coders, imagined audiences, predecessor apps, mobile devices, infrastructures, special cameras, architecture, bodies, and so on - actively negotiated how the MUM App would be re-made, some aspects were considered by Museum personnel as to not be up for negotiation. These included the branding of the Museum and its sponsors (such as names, logos and colors of choice), as well as the inclusion of both English and French language options (that ensured local language requirements were met according to regional linguistic laws)..$^{10}$ Of course, the McCord Museum also had to include digitized historical photographs from its own collections. But, there were also limited funds to contend with, and this rendered other aspects of design even less negotiable. So, aside from the branding, the language options, the collections on display and the location of the exhibit, the MUM App wound up having a similar design to the Streetmuseum App (i.e. the same user flow and aesthetics, such as graphics, fonts, and buttons). In comparing the two Apps in 2012 (as thereafter the Streetmuseum App was updated), they had more in common than not. Not only did both apps showcase only historical images that could be superimposed across cityscapes (the former in London and the latter in Montreal), but the user experience for both apps was practically identical: from the initial interface (and after selecting the language option on the MUM App), the user was presented with the "pinned card" used to navigate around the city in order to find the locations where historical images were on view. By selecting "pins" on the pinned card users could also view the historical images in similar 2-D views. By tapping on these images, similar displays, with titles and descriptions of the historical images, would be presented in both cases. And both apps had the same style of ' $3 \mathrm{D}$ View' buttons, which displayed the historical images in augmented reality. Now, the original design of the Streetmuseum App could have been changed when re-making the MUM App, but according to the Project Manager of Web and Multimedia, any major changes to the design would have been costly, and they were working with a tight budget.

When design changes are cost-prohibitive they become 'non-negotiable'. In ANT studies, this state of non-negotiation has been referred to as 'irreversibility' (Callon, 1991; Akrich et al. 2002) or a 'lock-in' effect (Urry, 2004; see also David, 1985). Callon discusses irreversibility as a type of stabilization of connections in a network and the 'extent to which they are predetermined' (1991: 133). Akrich et al, (2002) explain 'irreversibility' through the analogy of the successive passes on a Scrabble that saturate the board. Urry's (2004) use of the term lock-in describes how an infrastructural design leads to the locking of standards over time, not only as a result of network stabilization, but rather due to the material resources required to modify it, and which therefore renders changes cost prohibitive. One example of this is the persistent use of the 'QWERTY keyboard', despite it being, as David puts it, a 'standardization on the wrong system' (1985: 336, original emphasis). Another example is Urry's (2004) case study of the 'steel and petroleum car' as mode of transportation. As he explains, the steel and petroleum car reached lock-in given its related 'systems of provision and categories of things are "materialized" in a stable form' (Slater, 2001 in Urry, 2004: 26). For Urry examples of lockin show that institutions matter a great deal in how systems develop, and that they 'can have the effect of producing a long-term irreversibility' that is both predictable and difficult to reverse (2004: 32). This says a lot about "material" infrastructures, but what about "digital" ones? Well, more recently, Kitchin (2014) has also used lock-in in relation to the "corporatization of smart city governance' and he suggests the digital infrastructure of cities as increasingly shaped by corporate interests. Kitchin points to how smart city solutions are being pushed by vendors, creating 'a technological lock-in that beholden cities to particular technological platforms and vendors over a long period of time' (2014: 10). 
Given this case arguably shows a lock-in effect of a museum's "digital" display, we may feel it is not as problematic as, say, the environmental issues caused by petrol-based cars. But it becomes more serious when considering the way in which, more generally, the use of apps helps to stabilize the use of mobile and desktop devices (such as smartphones and tablets to use apps, as well as laptops and desktops to develop them), which, without recycling programs (such as Apple's GiveBack Program), could be contributing to environmental issues like technology dumping (for example, the Digital Dump in Africa) ${ }^{11}$. In this case, lack of significant funding and, on the flip side, expensive modifications to design, brought on irreversibility or lock-in of this augmented reality app. In turn, the apps, the networks within which they are embedded, as well as the practices associated with them, participate in stabilizing the use of "digital" infrastructures on a wider scale. The observations further reflect an increasing reliance on corporate organizations - not only in terms of their infrastructure but also for their direct sponsorships. For example, nine additional images that were eventually added to the MUM App's initial 141 images were a result of a collaboration with a property management organization named Ivanhoé Cambridge. ${ }^{12}$ But this is not something new in exhibition-making processes - as Macdonald's (2002) 'Sainsbury-sponsored' exhibit Food for Thought showed us.

While the McCord Museum had limited funding for this project, the Museum of London seemed to have had more resources, such as funds to draw on..$^{13}$ This is perhaps evidenced not only by the initial innovative design of the Streetmuseum App, but also in how the Streetmuseum App was deployed in two versions - one for iOS and the other for Android - making it more accessible to diverse platforms, devices and populations (unlike the MUM App, which was only released for iOS). Further, the Streetmuseum App was subsequently updated with sharper graphics and it featured special temporary exhibitions, including an augmented reality (promotional) display for the Cheapside Hoard exhibition in 2013. Further still, the Museum of London was able to release yet another augmented reality app called the Streetmuseum $^{\mathrm{TM}}$ Londinium App (hereon Londinium App). This App is perhaps even more innovative than the original Streetmuseum, incorporating a wider range of augmented reality features as described on the App Store:

The new app directs users to locations from Roman London where you can 'excavate' finds, using your fingers to dig and gradually reveal ancient artefacts where they were originally found. iPhone users can remove dirt by blowing into their microphone. Key Roman London sites, such as the amphitheater and Temple of Mithras, have been brought to life through augmented reality video (iPhone only) - produced by HISTORY ${ }^{\mathrm{TM}}$ - showing scenes of Roman London, overlaid onto the view today. A soundscape to the Roman capital is also included, so you can listen to the hustle and bustle of the forum or the clamour of the Boudican rebellion. In addition, a map of Roman London, compiled and produced by Museum of London Archaeology, has been superimposed on a modern map of London. Use the slider to see how the city has changed over the last 2,000 years. ${ }^{14}$

But such innovations were rendered cost-prohibitive for the McCord Museum. And when I last met the Head of IT and Project Manager of Web and Multimedia (in a follow-up meeting, in September of 2016) they admitted that they would soon discontinue the MUM App altogether. But, it seems the Museum of London's apps have had a similar (albeit perhaps temporary) fate - as the Streetmuseum App and the Londinium App are no longer available after "significant changes in recent operating system updates". ${ }^{15}$ This points to how "digital" museum displays can be a precarious business - demanding resources (human and nonhuman) in the continuous making and re-making of "digital" applications, devices and infrastructures.

\section{The Gatekeepers: Who Gets the Final Say?}

There are, perhaps always, 'gatekeepers' (Latour and Woolgar, 1979; Latour, 1987) in any process - those through whom or which decisions must pass - but what's interesting is who or what becomes a gatekeeper. At the McCord Museum, the Project Managers could be said to have become gatekeepers in terms of their ability to approve (or disapprove) of the content selected for the MUM App - as much as, for example, the test build app. But there are also 
those gates which only technical expertise, licenses and funding can establish. For example, since Thumbspark Ltd was the coder and "seller" of the App, and Brothers and Sisters acted as the agent between Thumbspark Ltd and the McCord Museum, any modifications to the MUM App must have involved both of these companies, positioning them also as gatekeepers. But perhaps most interesting is that the MUM App had to be designed and developed in accordance with the specifications of particular platforms - specifically, Apple platforms for developing (e.g Xcode), running (e.g iOS) and selling apps (on the App Store). Thus, Apple's vast 'black boxed' (Latour, 2005) infrastructures, became not only actors that negotiated the design of the MUM App, but also hidden gatekeepers to the App's design, development and sale. Ultimately, Apple must approve apps before they can be "sold" (even as a free app) through the App Store. This approval process by a technology company is part of the "digital" politics of display whereby corporate organizations and infrastructures not only negotiate what and how "digital" displays get made (intentionally or unintentionally), but can also have the last word on their design and sale.

The early Horizon Report that recommended developing location-based technologies and augmented reality apps never pointed to the problem of having to get apps approved by the online stores which would inevitably sell them. This brings me to one last point. A closer look reveals that these reports were actually developed by an organization, the NMC, founded in 1993 through a joint venture that included Apple Computers, Adobe, Macromedia and Sony, 'who realized that the ultimate success of their multimedia-capable products depended upon their widespread acceptance by the higher education community in a way that had never been achieved before. ${ }^{16}$ Here we find that the recommendation of technologies to the museum community was done by the very same companies whose devices and platforms develop, run and sell the very same apps they recommend. Given the NMC was made of commercial institutions, any recommendations it made should perhaps have also been considered as promotional. The findings here show that the Horizon Report (among other actors) worked not only to entangle museums with technologies and infrastructures as well as commercial players and products in unprecedented ways, but were also written by the branch organizations of the "new" gatekeepers established in app exhibitionary practices. ${ }^{17}$

\section{Conclusions}

This study has shown that, the MUM App emerged from the 'negotiations' of heterogeneous actors, what Bolter and Grusin (1999) call a 'remediation', a refashioning of an actor-network. The study also highlights the complex politics of how this has played out in practice for the McCord Museum's MUM App display. In particular, I am referring to the entanglements between the Museum and commercial institutions, but also changes in competing social, cultural, economic and political interests. For example, some transformations may perhaps reflect the politics of shifting interests in the Museum's mission from a focus on 'education' and 'research' in the past, to one that seeks to produce more 'contemporary, interactive and immersive experiences' into the twenty-first century, as historian Young (2000) suggested. But this case also points to how the "digital" politics of display lie, perhaps more interestingly, in the corporatization of digital infrastructures (as Kitchin, 2014, has argued in relation to 'smart' city governance), and how these are increasingly networked into museum exhibitionary practices. It's interesting, not because corporate involvement is new to exhibitionary practice (recall again the 'Sainsbury-sponsored' Food for Thought exhibit), but because power relations are hidden inside these vast black-boxed infrastructures. Within them, designs may be 'locked in' and "new" gatekeepers established, whereby corporate players, as much as code, frameworks and devices can have a (or the last) word on a museum's display. Again, the aim here is not to critique any particular actor - human or nonhuman! This is not an "us" versus "them" argument, as any such boundaries do not hold up to close scrutiny. Rather my aim here has been to reveal the actors and expose any 'un-reflected upon assumptions' that we may have.

This case has also brought to our attention the challenges and benefits of tracing processes of culture in the (re-)making with an understanding of digital media technologies as actor-networks. It is challenging, if not impossible, to trace all the actors involved and I therefore only traced a portion of the actors in this study. And while I traced actors both 'inside' and 'outside' the Museum, it is impossible to isolate the exterior from the interior, as Yaneva (2003) 
points out, especially with code, data, files, collections and so on moving there and back, and there and back again. But importantly, this 'symmetrical' analysis, which has examined both the social and the technical as well as human and nonhuman actors, has revealed the complex negotiations involved in re-making a "digital" display. These unveilings could have only been made based on an understanding of the App both as an actor-network and also as emerging in vast networks of heterogeneous actors - without such an understanding the entanglements made in the re-making of the App would likely not have been discerned.

Lastly, taking an ANT approach has shown that the "digital" is very much embedded in sociotechnical practices and processes, and these are couched in complex 'sociomaterial' arrangements (as Suchman, 2007, and Gillespie et al., 2014, have argued). This was evidenced, for example, in the process of selecting and arranging the MUMApp's display of digitized images (which was done in a material and tactile way by printing out images and laying them out on a map placed on a table) and in the process of collecting geo-locational information for the display (for which Museum personnel utilized their bodies to obtain the correct positioning of the camera device employed to capture this information). Thus, while such apps may appear to exist in an entirely "digital", and thereby "dematerialized", form they actually continue to be well embedded in "material" arrangements - they emerge and stabilize in networks that are as much related to standardized code, frameworks and operating systems as they are to spaces, buildings, mobile devices, maps and bodies. And within such precarious networks of heterogeneous actors and entangled arrangements we may find the politics of "digital" display.

Received: 29 June 2017

Finally Accepted: 30 July 2018

\section{Acknowledgements}

Thank you to the McCord Museum, and especially the Head of IT and the Project Manager of Web and Multimedia, who provided me with views into how the MUM App was re-made. Thank you also to the Digital Producer at Brothers and Sisters, and the developer at Thumbspark Ltd. who helped further piece things together. I am grateful for the feedback I received on earlier versions of this research work, and the comments made by anonymous reviewers.

\section{Notes}

1 For Yaneva, museum studies 'does not treat the museum as an institution that is simply concerned, in a neutral way, with classification, collection and conservation activities' rather it is 'a tool available to a society to find and to demarcate its identity; its role is to visualize cultures' (2003: 116). Thus, 'the museum is reduced to a "facade" of social differences and becomes a representation of dominant ideological interests' (Yaneva, 2003: 116).

2 As Yaneva notes, while anthropologists of material culture are concerned with the specificities of internal practices, 'the daily process of installing museum objects and negotiating their display in concrete situations is not often described' (2003: 117).

3 Although Barry's (1998) exploration of 'interactives' at the Science Museum and Harvey's (1998) discussion on 'technologies' and 'informatics' at Expo '92 could be considered as exceptions.

4 Since 22 January 2017, the permanent exhibit Montreal - Points of View is no longer on display.

5 As claimed in the McCord Museum's press release on August 30, 2011: http://www.mccordmuseum.qc.ca/pdf/PR/PR MUM EN.pdf last retrieved 28 July 2018. 
6 This information was posted on a blog by the Creative Cooperation in Cultural Heritage. The post, however, has since been removed from the website: http://chief.uc.pt/blog/index.php/ streetmuseum-a-successful-partnership-between-technology-and-cultural-heritage/ last retrieved 9 January 2012. But similar information was discussed in the Museum of London Governors' Report and Financial Statements for the year ended 31 March 2011, which noted that the Streetmuseum App had 'been a major success' given it was 'downloaded by 85,000 iPhone users within the first months, reaching 200,000 by the end of the year'. The Report can be found here: https://www.museumoflondon.org.uk/application/files/9514/5468/1037/ Museumof-London-Accounts-2011.pdf last retrieved 28 July 2018.

7 The white paper by Azavea and DOR 'Implementing Mobile Augmented Reality Technology for Viewing Historic Images' is available online at: $h$ ttp://2rct3i2488gxf9jvb1lqhek9-wpengine. netdna-ssl.com/wp-content/uploads/2016/05/Augmented Reality by PhillyHistory Whitepaper_v02.pdf last retrieved 24 July 2018.

8 Both the StreetmuseumApp and the MUMApp were meant to act (and in particular situations were performed or enacted) as 'exhibit displays' and 'promotional tools'. Thus we may consider these apps as what Star and Greismer (1989) call 'boundary objects' - i.e. they have 'variable ontology' (Latour, 1991 in Yaneva, 2003) and require successful points of 'translation' to stabilize in practice (Callon, 1986, 1999; Star and Greismer, 1989). However, stabilization as this thing or the other is always debatable and uncertain - a precarious process.

9 The Sony HX5V has both a built-in GPS receiver and compass that allows it to tag images with the location and direction of the camera. Tag information is used by the iPhone's software to display images on a map by location.

10 But some laws seemingly allowed for negotiations to take place. In this case, the app's copyright held by Thumbspark Ltd, who was re-hired to re-make the MUM App, allowed for the developer to reuse the code initially written for the Streetmuseum App.

11 The Digital Dump is described in the Basel Action Network report available online at: $\underline{\text { http:// }}$ ban.org/films/TheDigitalDump.html last retrieved 28 July 2018

12 The McCord Museum has made only one significant update to the MUM App since its release, when it added four outdoor images of Place Ville Marie, 1000 de la Gauchetière, the Centre de commerce mondial and Fairmont The Queen Elizabeth as well as five indoor images in Place Montréal Trust, Complexe Les Ailes, Place Ville Marie, Centre CDP Capital, and 1000 de la Gauchetière as a result of a partnership formed with Ivanhoé Cambridge. The press release was available online at: http://www.musee-mccord.qc.ca/ pdf/PR/PR Musee-McCord-etend-son-application-Musee-Urbain EN.pdf last retrieved 22 July 2015 - but has been since removed.

13 Though not a perfect comparison, the Museum of London Group (which includes the Museum of London, Museum of London at London Wall, Museum of London Docklands, and Museum of London Archaeology (MOLA), a division of the Museum of London) reported incoming funds of $£ 32,053,000$ (GBP) in the 2010/2011 fiscal year, whereas the McCord Museum reported \$5,366,228 (CDN) in 2011 (about one tenth the amount after calculating foreign exchange at a conversion rate of about 1.7). This information is made public in the museums' annual reports and is available on their respective websites: http:// www.musee-mccord.qc.ca/en/annual-reports/ and https://www.museumoflondon.org.uk/ about-us/corporate-information/annual-reports-and-accounts last retrieved 28 July 2018.

14 The Streetmuseum ${ }^{\mathrm{TM}}$ Londinium App and a description of its features were available online at: https://itunes.apple.com/us/app/streetmuseum-londinium/id449426452? mt=8 last retrieved 21 September 2015 - but have since been removed. 
15 As described on the Museum of London website: https://www.museumoflondon.org.uk/ discover/museum-london-apps last retrieved 28 July 2018.

16 As described on the New Media Consortium website: http://www.nmc.org/about/nmchistory/ last retrieved July 24, 2018. (Note that the New Media Consortium website is now archived, see also endnote 16).

17 As of February 2018, The New Media Consortium (NMC) was acquired by EDUCAUSE. An analysis of how the NMC and its reports have been incorporated (or not) into the particular organization and mission of EDUCAUSE is beyond the scope of this paper.

\section{References}

Akrich, M. (1992) 'The De-Scription of Technical Objects', in Wiebe E. Bijker and John Law, (eds.) Shaping Technology/Building Society: Studies in Sociotechnical Change, 205-224, Cambridge, MA: MIT Press.

Akrich, M., Callon, M. and Latour, B. (2002) 'The Key to Success in Innovation Part I: The art of Interessement', International Journal of Innovation Management, 6 (2) 187206.

Barry, A. (1998) 'On interactivity: Consumers, citizen and culture', in Sharon Macdonald (ed.) The Politics of Display: Museums, Science, Culture, 98-117, London: Routledge.

Bijker W. E. and Law J. (eds.) (1992) Shaping Technology/Building Society: Studies in Sociotechnical Change, 290-308, Cambridge, MA: MIT Press.

Bolter, J. and Grusin, R. (1999) Remediation: Understanding New Media, Cambridge: MIT Press.

Bowker, G. C. and Star, S. L. (1999) Sorting Things Out: Classification and its Consequences, Cambridge, MA: MIT Press.

Boyer, D. and Marcus, J. (2011) 'Implementing Mobile Augmented Reality Applications for Cultural Institutions', in Jennifer Trant and David Bearman (eds) Museums and the Web 2011: Proceedings. Toronto: Archives \& Museum Informatics. Published March 31, 2011. Available online http://www.museumsandtheweb.com/mw2011/papers/ implementing mobile augmented reality applicat last retrieved on July 24, 2018

Callon, M. (1986) 'The Sociology of an Actor-Network: The Case of the Electric Vehicle', in Michel Callon, John Law \& Arie Rip, (eds.), Mapping the Dynamics of Science and Technology, 19-34, Basingstoke: MacMillan.

(1991) 'Techno-economic networks and irreversibility' in John Law. (ed.) A Sociology of Monsters: Essays on Power, Technology and Domination, 132-161, London: Routledge.

(1999) 'Some Elements of a Sociology of Translation: Domestication of the Scallops and the Fisherman of St. Brieuc Bay', in Mario Biagioli (ed.), The Science Studies Reader, 67-83, New York: Routledge.

David, P. (1985) 'Clio and the economics of QWERT', American Economic Review (Papers and Proceedings of the Ninety-Seventh Annual Meeting of the American Economic Association), 75 (2), 332-337. 
Gillespie, T., Boczkowski, P. J. and Foot, K. A. (2014) 'Introduction' in Tarleton Gillespie, Pablo J. Boczkowski and Kirsten A. Foot, (eds.) Media Technologies: Essays on Communication, Materiality, and Society, 1-17, Cambridge, MA: MIT Press.

Harvey, P. (1998) 'Nations on display: Technology and culture in Expo '92', in Sharon Macdonald (ed.) The Politics of Display: Museums, Science, Culture, 139-158, London: Routledge.

Henning, M. (2006) Museums, Media and Cultural Theory, Maidenhead: Open University Press.

(2007) 'Legibility and Affect: Museums as New Media' in Sharon Macdonald and Paul Basu, (eds.), Exhibition Experiments, 25-46, Oxford: Blackwell Publishing.

(2011) 'New Media', in S. Macdonald (ed.). A Companion to Museum Studies. 302318, Oxford: Wiley-Blackwell.

Johnson, L., Witchey, H., Smith, R., Levine, A., and Haywood, K. (2010) The 2010 Horizon Report: Museum Edition, Austin, Texas: The New Media Consortium.

Kitchin, R. (2014) 'The real-time city? Big data and smart urbanism', GeoJournal, 79 (1) $1-14$.

Latour, B. (1987) Science in Action: How to follow scientists and engineers through society, Cambridge, MA: Harvard University Press.

(1991) Nous n'avons jamais été modernes. Essai d'anthropologie symétrique, Paris: La Découverte.

(1991) 'Technology is society made durable' in John Law (ed.) A Sociology of Monsters: Essays on Power, Technology and Domination, 103-131, London: Routledge.

(1994) 'On Technical Mediation - Philosophy, Sociology, Genealogy', Common Knowledge, 3 (2) 29-64.

(2005) Reassembling the Social: An Introduction to Actor-Network-Theory, Oxford: Oxford University Press.

Latour, B. and Woolgar, S. (1979) Laboratory Life: The Construction of Scientific Facts, Princeton, NJ: Princeton University Press.

Law, J. (1991) 'Introduction: monsters, machines and sociotechnical relations' in John Law (ed.) A Sociology of Monsters: Essays on Power, Technology and Domination, 1-23, London: Routledge.

(2007) 'Actor Network Theory and Material Semiotics', version of April 25, 2007. Source: http://www.heterogeneities.net/publications/ Law2007ANTandMaterialSemiotics.pdf last retrieved September 28, 2015

(2008) 'On Sociology and STS', The Sociological Review, 56 (4) 623-649.

Law, J. and Bijker, W. (1992) 'Postscript: Technology, Stability, and Social Theory', in Wiebe E. Bijker and John Law (eds.) Shaping Technology/Building Society: Studies in Sociotechnical Change, 290-308, Cambridge, MA: MIT Press. 
Lister, M., Dovey, J. Giddings, S. Grant, I. and Kelly, K. (2009) New Media: A Critical Introduction, Second Edition. Oxon: Routledge.

Macdonald, S. (ed.) (1998) The Politics of Display: Museums, Science, Culture, London: Routledge.

(1998a) 'Exhibitions of power and powers of exhibition: An introduction to the politics of display' in Sharon Macdonald (ed.) The Politics of Display: Museums, Science, Culture, 1-24, London: Routledge.

(2002) Behind the Scenes at the Science Museum, Oxford: Berg.

Mason, M. (2015) 'Prototyping practices supporting interdisciplinary collaboration in digital media design for museums', Museum Management and Curatorship, 30 (5) 394-426.

(2016) 'The MIT museum glassware prototype: Visitor experience exploration for designing smart glasses' ACM Journal on Computing and Cultural Heritage, 9 (3) $1-29$

Olesen, A. (2016) 'For the sake of technology? The role of technology views in funding and designing digital museum communication', Museum Management and Curatorship, 31 (3) 283-298.

Parry, R. (2007) Recoding the Museum: Digital Heritage and the Technologies of Change, Abingdon, Oxon: Routledge.

(ed.) (2010) Museums in a Digital Age, Abingdon, Oxon: Routledge.

Rubio, D. (2012) 'The Material Production of the Spiral Jetty: A Study of Culture in the Making', Cultural Sociology, 6 (2) 143-161.

Slater, D. (2001) 'Markets, materiality and the 'new economy', paper given to 'Geographies of New Economies' Seminar, Birmingham, UK, October.

Smørdal, O., Stuedahl D., and Sem, I. (2014) ‘Experimental Zones: Two Cases of Exploring Frames of Participation in a Dialogic Museum', Digital Creativity 25 (3) 224-232.

Star, S. L. and Greismer, J. (1989) 'Institutional Ecology, 'Translations' and Boundary Objects: Amateurs and Professionals in Berkeley's Museum of Vertebrate Zoology, 1907-39', Social Studies of Science, 19 (3) 387-420.

Stuedahl, D. and Smørdal, O. (2011) 'Re-thinking museum assemblies', Conference paper presenting in May 2011, available online at: https://www.researchgate.net/ publication/233416673_Re-thinking_museum_assemblies last retrieved 28 July 2018

Suchman, L. (2007) Human-Machine Reconfigurations: Plans and Situated Actions, $2^{\text {nd }}$ Edition, New York, NY: Cambridge University Press.

Urry, J. (2004) 'The "System” of Automobility', Theory Culture Society, 21 (4/5) 25-39.

Yaneva, A. (2003) 'When a Bus Met a Museum: Following Artists, Curators and Workers in Art Installation', Museum and Society, 1 (3) 116-131. 
Young, B. (2000) The Making and Unmaking of a University Museum: The McCord, 19211996, Montreal: McGill-Queen's University Press.

${ }^{*}$ Dr. Ana-Maria Herman is an Assistant Professor in Information Technology Management at Ted Rogers School of Business, Ryerson University. Her research draws on her background in politics, management and sociology to explore the use of novel technologies across museums, libraries and heritage institutions and examine their social, practical and political implications.

Ana Maria Herman, PhD, Assistant Professor Information Technology Management Ted Rogers School of Business

Ryerson University

350 Victoria Street, Toronto, ON Canada, M5B 2K3

Email: anamaria.herman@ryerson.ca

Tel: (416) 979-5000 x7523 